\title{
EXPERIMENTAL INFECTION OF Leishmania chagasi IN IMMUNOSUPPRESSED BALB/C MICE: CELLULAR IMMUNE RESPONSE AND PARASITE BURDEN
}

Thesis: J. L. Hoffmann submitted this dissertation for his Masters in Tropical Diseases at Botucatu Medical School, São Paulo State University, UNESP, Botucatu, São Paulo State, Brazil, 2008.

Advisor: Professor Helio Langoni

ABSTRACT: The immune response to leishmaniasis can result in a polarization of a subpopulation of $T$ lymphocytes, which leads to a different cell phenotype and results in immune protection or exacerbation of the disease. Leishmanias persist in the body both in asymptomatic infections and after treatment, representing risks in terms of immunosuppression. The objective of this study was to evaluate the effects of infection and immunosuppression by dexamethasone associated with pentoxifylline on animal weight, spleen weight, the parasitic load in the spleen and liver, as well as the production of IFN-y and IL-10 in spleen cell culture of Balb/c mice infected with Leishmania chagasi. The infection did not alter animal weight gain, but spleen weight and size increased. The immunosuppression, induced by dexamethasone associated with pentoxifylline, affected animal weight gain and weight and size of the spleen (in infected and not infected animals). The immunosuppression did not significantly alter the course of the parasite burden in the spleen and liver. Dexamethasone and pentoxifylline affected the studied cytokine production, but not influenced on Th1/Th2 response in infected animals.

KEY WORDS: Leishmania chagasi, immunosuppression, cell mediated response, parasite burden, experimental infection.

\section{CORRESPONDENCE TO:}

JULIANO LEÔNIDAS HOFFMANN, Departamento de Doenças Tropicais, Faculdade de Medicina, UNESP, Botucatu, SP, Brasil. Phone: +55 143811 6379. Fax: +55 14 3815 9898. Email: hoffmann1804@yahoo.com.br. 